\title{
Iranian Adolescents With Physical-Motor Disabilities: Needs and Problems in Education and Employment
}

\author{
Mehdi Sharifi ${ }^{1}$, Mohammad Rostami ${ }^{1}$, Seyed Jalal Younesi ${ }^{1}$, Maryam Sharifian Sani ${ }^{2}$, Giuta Movallali ${ }^{3,4^{*}}$ \\ 1. Department of Counseling, University of Social Welfare and Rehabilitation Sciences, Tehran, Iran. \\ 2. Department of Social Welfare, University of Social Welfare and Rehabilitation Sciences, Tehran, Iran. \\ 3. Department of Exceptional Children, University of Social Welfare and Rehabilitation Sciences, Tehran, Iran \\ 4. Pediatric Neurorehabilitation Research Center, University of Social Welfare and Rehabilitation Sciences, Tehran, Iran.
}

Cftaton: Sharifi M, Rostami M, Younesi SJ, Sharifian Sani M, Movallali G. Iranian Adolescents With Physical-Motor Disabilities: Needs and Problems in Education and Employment. Iranian Rehabilitation Journal. 2016; 14(2):101-107. https://doi.org/10.18869/nrip.irj.14.2.101

: https://doi.org/10.18869/nrip.irj.14.2.101

Article info:

Received: 09 Mar. 2016

Accepted: 01 Jun. 2016

\section{Keywords:}

Physical-motor disabilities, Problems, Needs, Employment, Education

\section{A B S TRACT}

Objectives: The needs and problems of students with physical-motor disabilities should be properly identified in order to solve them. The main purpose of this research was to determine the needs and problems of Iranian male students with physical-motor disabilities in the education and employment dimensions.

Methods: This was a descriptive study. All the male students with physical-motor disabilities were selected from the special high schools of Tehran, Iran, in the year 2013-14 as a statistical research community. Of all, only 150 male students with physical-motor disabilities were chosen by convenience sampling method. An edited version of the questionnaire from a previous study on the needs and problems of girls and women was used for this study.

Results: According to our results, the main needs of the students in the employment dimension include transportation services, specific training courses, and quotas for employment. However, the main problems in the employment dimension include displacement and transportation problems, and lack of policy enforcement. Similarly, the priority needs in the education dimension include community education and professional training, whereas the priority problems include displacement and transportation problems.

Discussion: The results of this study indicated a variety of problems and needs of the Iranian students with physical-motor disabilities, indicating the requirement of planning and policies to address them.

\section{Introduction}

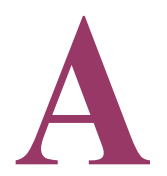

ccording to the World Health Organization, disability has been described as a restriction or inability (resulted from an impairment) to perform any activity in a particular manner that can be considered as normal for a human being [1]. One such disability is the physicalmotor disability, which refers to the weakness or failure in the movement system of individuals that results in the inability to move their body parts or need for mobility aids [2]. According to the data from World Health Organization, approximately 650 million people, i.e. about $10 \%$ of the world population, suffer from physical dis-

* Corresponding Author:

Giuta Movallali, PhD

Address: Department of Exceptional Children, University of Social Welfare and Rehabilitation Sciences, Koodakyar Ave., Daneshjoo Blvd., Evin, Tehran, Iran. Tel: +98 (912) 3758437

E-mail: drgmovallali@gmail.com 
ability; and more than two-thirds of these people live in the developing countries. According to the population and housing census in 2006 statistics, 450 thousand people, aging below 25 years, have been declared to be disabled. On the other hand, experts believe that the total number of the country's disabled people of all age groups is about 12 million and 800 thousand [3].

Students and children with disability are widely considered as one of the most vulnerable groups in schools and society. Studies have consistently shown that the disabled students are at a greater risk of experiencing poor educational and psycho-social conditions [4, 18]. Results of the Sharifian Sani's study in the field of education [5] showed that girls with physical-motor disability face more problems due to the lack of educational resources. In addition, Ren's finding [6] showed that $83 \%$ of disabled students had less academic progress than $50 \%$ of their normal peers; and more than half of the disabled students had less academic progress than $25 \%$ of the normal students of their own school. These students are also more vulnerable to psychological problems like depression, anxiety, substance abuse problems [7], and even suicide [8]. The sociological findings also suggest a pessimistic view or a kind of social stigma towards disabled people [9]. For physical-motor disabled students, there is a need to receive specific training during the early years of education in order to acquire a skill, especially for those who are preparing to enter into the world of employment [10].

Movement and dynamism of physical-motor disabled people can be of importance both for them and the society. They improve both health and performance, resulting in a high degree of independence in people with disability, thereby, reducing the demand for social support from the community. Lack of awareness among the common mass about the abilities of the disabled people creates a problem for the society itself. This need for movement and dynamism is acceptable and desirable from both economic and moral perspectives [11].

To some extent, people are defined by their quality of work in life, and employment is greatly associated with this concept [12-14]. There are varied reasons for the low participation of disabled people in both social and professional areas. The employment sector includes both environmental and individual barriers. Environmental barriers include inadequate governments' policies, lack of access to professional rehabilitation services, inadequate or unavailability of public transport, limited employment opportunities in the labor market, and the social stigma associated with disability. On the other hand, individual barriers include restrictions in ed- ucation, lack of professional experience, and insufficient job skills. The major individual barrier is the severity of pain associated with the functioning and poor health conditions of the disabled patients [15].

Providing adequate education and employment opportunities for self-dependency of the disabled people remains a problem in the society [16]. In 2007, it was found in a study that the employment rate of physical-motor disabled people was about $36.9 \%$ compared to that of $80 \%$ in normal people. Out of $63.1 \%$ of unemployed disabled people, only $8.4 \%$ were actively looking for work [1].

Elimination of discrimination against disabled students and providing them both educational and professional opportunities is only possible by recognizing their needs and problems. This can be detected from the primary data related to their social and professional life and collected from the country-wide researches conducted on people with disability after their rehabilitation [5]. Although studies have been conducted earlier in this area, the difference in the studied population [5] and dimensions [17] distinguish the present study from the other studies.

According to the present survey, identifying the needs and problems of the disabled people can provide a clear picture of their life. It can aid in future researches on this group of individuals and the authorities, which can affect the future policies. Therefore, the aim of this study is to determine the needs and problems of employment and training of physical-motor disabled students.

\section{Methods}

The present descriptive study was conducted on male Iranian students in the academic year of 2014-2015 who were suffering from a physical-motor disability. The statistical population consisted of exceptional male students of Tehran high schools, of which 150 students were selected through convenience sampling. Data were collected through the edited version of the questionnaire that was used in a similar study on the needs and problems of women and girls with physical-motor disabilities in Iran [5]. This questionnaire consisted of 82 questions to assess their current situation as well as needs and problems. It also included queries about employment, education, marriage, communication, traffic, leisure, economy, and violence. The Cronbach's alpha coefficient of the questionnaire for reliability was $76 \%$, and its content validity was approved by the experts [5]. The questionnaires were distributed among the selected exceptional male students of three high schools in Tehran (i.e. Educational Complex Haj Babaei, Soroush, and Imam Ali). 
After receiving permission from the Ministry of Education in Tehran, the sampling process was conducted in coordination with the coaches and in agreement with parents and participants (including their written informed consent). Students with physical-motor disabilities underwent stages of interviews and questionnaires conducted by the male and female researchers. Before initiating the study, consent was taken from the University of Social Welfare and Rehabilitation Sciences Ethics Committee after a detailed explanation of the nature, purpose, and confidentiality of the results. It was also assured that people could withdraw from the study whenever they want, and no one will be forced to participate. The identity and information of the participants will remain confidential, and the results obtained will be made available for people and institutions with their consent only. The data obtained through questionnaire was analyzed using descriptive statistics.

\section{Results}

The results were examined in two parts; the first part showed a general picture of the population on various dimensions, and the later focused on the needs and prob- lems of the participants. The most important characteristics of student include: disability not being progressive (80\%), Consanguineous of parents together $(66.6 \%)$, Education level high school (100\%), Using services (3.54\%) and belonging to the lower socio-economic classes $(75 \%)$ (Table 1).

The findings of the study pointed out the lack of training courses, transport services, and support from society as major problems in both education and employment sectors of the physical-motor disabled students/people. The main problems and needs of students who have studied in the employment dimension are presented in Table 2. The main needs for students in the employment dimension include: transportation services (88.8\%), Existence of specific quotas for employment (95\%) and the main problems of students in the employment dimension include: transportation and traffic $(70.7 \%)$ and lack of policy enforcement (35\%).

As per the participants, the priority needs for education includes the availability of training resources and proper transportation services to it. Moreover, the employment

Table 1. Demographic information of studied population students.

\begin{tabular}{|c|c|c|c|}
\hline $\begin{array}{l}\text { The Overall Picture of People With Disabilities } \\
\text { in Various Dimensions }\end{array}$ & $\%$ & $\begin{array}{l}\text { The Overall Picture of People With } \\
\text { Disabilities in Various Dimensions }\end{array}$ & $\%$ \\
\hline Quantity of received services & $60 \%$ & Main cause of disability due to illness & $50.1 \%$ \\
\hline Using services & $3.54 \%$ & The quality of received services & $48 \%$ \\
\hline Physical symptoms due to disability & $30 \%$ & No other disease except disability & 65.6 \\
\hline 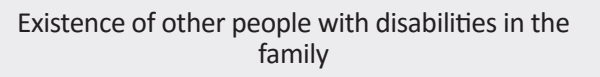 & $29 \%$ & Disability not being progressive & $80 \%$ \\
\hline Good or very good health status & $41.12 \%$ & Consanguineous of parents together & $66.6 \%$ \\
\hline Bad or very bad health status & $21.8 \%$ & Medium health status & $38 \%$ \\
\hline Sports activities & $39 \%$ & $\begin{array}{l}\text { Moderate satisfaction with the current } \\
\text { state }\end{array}$ & $39 \%$ \\
\hline Aged between 20-23 year & $40 \%$ & $\begin{array}{l}\text { Low and very low satisfaction with the } \\
\text { current situation }\end{array}$ & $32.4 \%$ \\
\hline Moderate severity of disability & $60.2 \%$ & The ages ranged between $14-20$ years & $60 \%$ \\
\hline Belonging to the lower socio-economic classes & $75 \%$ & Education level high school & $100 \%$ \\
\hline--- & ---- & Severe disability & $38.8 \%$ \\
\hline
\end{tabular}


Table 2. Major problems and needs of the student in the studied population for employment.

\begin{tabular}{|c|c|c|c|}
\hline Variable & Dimension & Subsets & $\%$ \\
\hline \multirow{3}{*}{ Problems } & & Transport and traffic & $70.7 \%$ \\
\hline & Employment & Absence of performance and support for the employment of disabled people & $35 \%$ \\
\hline & & Limitation of physical environment of work & $34.3 \%$ \\
\hline \multirow{3}{*}{ Need } & & Transport service to the workplace & $88.8 \%$ \\
\hline & Employment & Existence of specific quotas for employment & $95 \%$ \\
\hline & & Appropriate job according to your disability & $55.5 \%$ \\
\hline
\end{tabular}

Iranian Rehabilitation Journal

Table 3. Main problems and needs of the students in studied population for education.

\begin{tabular}{llcc}
\hline Variable & Dimension & Subsets & $\%$ \\
\hline \multirow{2}{*}{ Problems } & Education & Transport and traffic & $78 \%$ \\
& & The lack of training resources and facilities & $22 \%$ \\
& & Community education & $60 \%$ \\
Need & Education & Professional training & $49.7 \%$ \\
& & Family training & $45.9 \%$ \\
\hline
\end{tabular}

Iranian Rehabilitation Journal

sector also needs reservation system, adequate job opportunities, and transport service. The main problems and needs of students who have studied in the education dimension are presented in Table 3. The main needs in the education dimension include: Community education $(60 \%)$, professional training (49.7\%), and the main problems of students in the education dimension include: transport and traffic (78\%).

\section{Discussion}

Although there are limited numbers of academic and scientific researches in this aspect, the results of Sani Sharifian et al. [5] is consistent with this study with minute changes in the percentage of problems and priority needs. The present study results are also consistent with the findings of Henry and colleagues [15], as they also found the problems of inadequate public transport, limited employment opportunities, and lack of training courses, experience, and job skills in students with a physical-motor disability.

Few considerable points were noted from the study results, which included the onset time of disability in the participants (with a mean value of 4.8 years), which is the leading cause of the disease $(50.1 \%)$. Twenty-nine percent of the study population was found to have another family member with a disability, out of which the parents of $66 \%$ participants had consanguineous unions. The study findings pointed out the importance of firstlevel prevention of disability in many cases. About 30\% of respondents said that their complications influenced them to pay attention to secondary and tertiary levels of prevention of disability.

The students with a physical-motor disability also had to deal with the education and employment problems. Because these need in most of the questions in the questionnaire had been focused and attention and which means that students need of others' awareness of their ability to deal with the limitations of ordinary people without pity. In addition, the study highlighted the importance of removing the social barriers. Policy makers and planners can grab these opportunities to initiate practical actions in order to overcome the barriers and formulate steps to facilitate the participation of such people in the society. It could be one of the main solutions to the discrimination against the people with disabilities in the society [5] 
The negative attitude towards the disabled people [9], [15] and the lack of awareness in this regard [11] can be some of the other causes behind the delay in participation and limited attentions towards the people with disability. The transportation problems in the field of education and employment opportunities of these people also point to the lack of urban planning standards in accordance with the requirements of the people with disabilities. The findings of weakened planning and inefficient policies are consistent with the findings of Sharifian Sani [5] and Henry et al. [15].

The questionnaires stated that there was lack of employment options for the people with disability, and no attempt was made in this aspect. This attitude can be due to the difference in the needs and problems of both the people with disability and the society.

In order to remove the barriers and restrictions against the individuals with a disability, society must strive with practical action. The disabled people should be facilitated with plans and policies for their participation in society, which were also consistent with the findings of Thomas and Ellis [1] and Sharifian Sani et al. [5].

This study concluded that the main employment needs of disabled students are a lack of transportation facilities to workplace, employment quotas, and suitable job considering their disability. The findings of this study also deduced that there is a need for social policies and planning along with the allocation of resources, infrastructure, and basic principles to seek attention to this isolated group in the society. In some communities, the existing capacity, including people with disabilities not as affected individuals, but as a rich source of manpower for the development of society, and they are valuable citizens.

In this study, it was also found that the needs of the disabled people include proper education and professional training. Several studies have also supported that there is a requirement to educate the family of the disabled people about this ailment $[4,6]$.

It would be more effective if the provisions of educational training for the people with physical-motor disabilities are provided from an early age. It will not only strengthen their mental health but also help them in skill acquisition for entering into the world of work [10]. In order to raise awareness about the needs and limitations of disabled people in the community, they should themselves be aware of their own abilities. Hence, these disabled people can also be encouraged to join hands in spreading awareness in the society through varied educational, artistic, entertaining, and media programs, which will in return provide them opportunities to recognize their potentials and flourish their talents in their desired fields. It can also help in changing the attitude of the society and their family towards disability and disabled people.

In Iran, the lack of vocational rehabilitation services is also one of the most important needs of people with disabilities [15]. Therefore, providing educational materials and specific training courses to general practitioners and health care professionals about the needs and problems of the people with disability can help them while planning for the vocational aspects of the disabled people. The use of professional rehabilitation programs can also help the disabled people in finding a suitable job and promoting their participation in the world of work.

\section{Conclusion}

The study results not only reflect the diversity of the problems and needs of Iranian students with physicalmotor disabilities but also illustrate the difference between the priority needs and problems in the fields of education and employment. The main limitation of this study was the less number of study population caused by long absences and less attendance in the schools. In particular, the students with a disability caused by spinal cord injury were not able to participate in the program.

Conclusively, we suggest that both social and academic interventions are needed to be organized by counselors and psychologists based on professional rehabilitation programs for the development of mental and physical health of the people with disability.

\section{Acknowledgments}

The authors appreciate all the students for their participation in the survey. We hope that this research could help research institutions and the public take a step further by seeking their attention towards the needs and problems of disabled students. The current research hasn't received any financial support.

\section{Conflict of Interest}

The authors declared no conflict of interests. 


\section{Reference}

[1] Thomas KC, Ellis AR. Patterns of healthcare use and employment among people with disabilities. Disability \& Health Journal. 2013; 6(2):133-40. doi: 10.1016/j.dhjo.2012.11.008

[2] Brown RL, Turner RJ. Physical disability and depression: clarifying racial/ethnic contrasts. Journal of Aging \& Health. 2010; 22(7):977-1000. doi: 10.1177/0898264309360573

[3] Ghavamabadi M. [Supporting people with disabilities in international law (Persian)]. Social Welfare Quarterly. 2011; 11(41):307-41

[4] Humphrey N, Lendrum A, Barlow A, Wigelsworth M, Squires G. Achievement for All: Improving psychosocial outcomes for students with special educational needs and disabilities. Research in Developmental Disabilities. 2013, 34(4):1210-225. doi: 10.1016/j.ridd.2015.05.010

[5] Sharifian Sani M, Sajjadi H, Toloee F, Kazem-nezhad A. [Girls and women with motor-physical disabilities: needs and problems (Persian)]. Journal of Rehabilitation. 2006; 7(2):41-48.

[6] Ren L. Educational performance of foster children with disabilities in Taiwan. Procedia-Social \& Behavioral Sciences. 2010; 2(2):825-29. doi: 10.1016/j.sbspro.2010.03.111

[7] Mendes P, Snow P. The needs and experiences of young people with a disability transitioning from out-of-home care: The views of practitioners in Victoria, Australia. Children \& Youth Services Review. 2014; 36:115-23. doi: 10.1016/j.childyouth.2013.11.019

[8] Stephen S, O'Connor S, Dinsio K, Wang J, Russo J, Frederick $\mathrm{P}$, et al. Correlates of suicidal ideation in physically injured trauma survivors. Suicide \& Life-Threatening Behaviors. 2014; 44(5):473-85. doi: 10.1111/sltb.12085

[9] Scheid TL. Stigma as a barrier to employment: mental disability and the Americans with disabilities act. International Journal of Law \& Psychiatry. 2005; 28(6):670-90. doi: 10.1016/j. ijlp.2005.04.003

[10] Azlan AL, Rashid RM. Employment core abilities skills among trainees with physical disabilities in Malaysia. Procedia- Social \& Behavioral Sciences. 2013; 93:1760-765. doi: 10.1016/j.sbspro.2013.10.112

[11] Falkmer T, Henriksson P, Gregersen NP, Bjurulf P. Driver education for persons with cerebral palsy-a retrospective study of educational problems. Transportation Research Part F: Traffic Psychology \& Behaviour. 2000; 3(1):15-27. doi: 10.1016/s1369-8478(00)00011-5

[12] Laborde-Castérot H, Donnay C, Chapron J, Burgel PR, Kanaan R, Honoré I, et al. Employment and work disability in adults with cystic fibrosis. Journal of Cystic Fibrosis. 2012 11(2):137-43. doi: 10.1016/j.jcf.2011.10.008

[13] Hall JP, Kurth NK, Hunt SL. Employment as a health determinant for working-age, dually-eligible people with disabilities. Disability \& Health Journal. 2013; 6(2):100-06. doi: 10.1016/j.dhjo.2012.11.001

[14] Dotson WH, Richman DM, Abby L, Thompson S, Plotner A. Teaching skills related to self-employment to adults with developmental disabilities: An analog analysis. Research in Developmental Disabilities. 2013; 34(8):2336-350. doi: 10.1016/j.ridd.2013.04.009
[15] Henry AD, Long-Bellil L, Zhang J, Himmelstein J. Unme need for disability-related health care services and employment status among adults with disabilities in the Massachusetts medicaid program. Disability \& Health Journal. 2011; 4(4):209-18. doi: 10.1016/j.dhjo.2011.05.003

[16] Luftig RL, Muthert D. Patterns of employment and independent living of adult graduates with learning disabilities and mental retardation of an inclusionary high school vocational program. Research in Developmental Disabilities. 2005; 26(4):317-25. doi: 10.1016/j.ridd.2003.08.001

[17] Sharifi M, Younesi SJ, Movallali G, Mohammad-Aminzadeh D, Rostami M. Needs and problems of students with physical-motor disabilities in transportation, communication, bullying and leisure-time. Asian Journal of Education and eLearning. 2015; 3(4):297-305.

[18] Adib-Sereshki N, Saleh-Pour Y. [The acceptance of students with physical disabilities by their peers in inclusive and non-inclusive schools in Tehran (Persian)]. Rehabilitation Journal. 2005; 6(2):29-35. 